\title{
Livros Adquiridos
}

\section{ASTE}

BETTENSON, Henry. Documentos da igreja cristã. São Paulo: ASTE/ Simpósio, 1998, ISBN 85-86825-01-8.

\section{Ciudad Neuva}

BRAY, G. (Org.). 1-2 Corintios. La Biblia Comentada por Los Padres de la Iglesia. Novo Testamento 7. Madrid, Bogotá, Buenos Aires, México, Montevideo e Santiago: Ciudad Neuva, 2001, 472p., ISBN 978-849715-003-1.

BRAY, G. (Org.). Santiago, 1-2 Pedro, 1-3 Juan, Judas. La Biblia Comentada por Los Padres de la Iglesia. Novo Testamento 11. Madrid, Bogotá, Buenos Aires, México, Montevideo e Santiago: Ciudad Neuva, 2002, 360p., ISBN 978-84-9715-020-1.

CONTI, M. (Org.). 1-2 Reyes, 1-2 Crónicas, Esdras, Nehemías. La Biblia Comentada por Los Padres de la Iglesia. Antigo Testamento 5. Madrid, Bogotá, Buenos Aires, México, Montevideo e Santiago: Ciudad Neuva, 2015, 528p., ISBN 978-84-9715-318-8.

EDWARDS, M. J. (Org.). Colocenses, 1-2 Tesalonicenses, 1-2 Timótelo, Tito, Filemón. La Biblia Comentada por Los Padres de la Iglesia. Novo Testamento 9. Madrid, Bogotá, Buenos Aires, México, Montevideo e Santiago: Ciudad Neuva, 2002, 512p., ISBN 978-84-9715-013-2.

ELLIOT, M. W. (Org.). Isaías 40-66. La Biblia Comentada por Los Padres de 
la Iglesia. Antigo Testamento 13. Madrid, Bogotá, Buenos Aires, México, Montevideo e Santiago: Ciudad Neuva, 2014, 456p., ISBN 978-849715-297-6.

ELOWSKY, J. C. (Org.). Evangelio según San Juan (1-10). La Biblia Comentada por Los Padres de la Iglesia. Novo Testamento 4a. Madrid, Bogotá, Buenos Aires, México, Montevideo e Santiago: Ciudad Neuva, 2012, 544p., ISBN 978-84-9715-252-5.

ELOWSKY, J. C. (Org.). Evangelio según San Juan (11-21). La Biblia Comentada por Los Padres de la Iglesia. Novo Testamento 4b. Madrid, Bogotá, Buenos Aires, México, Montevideo e Santiago: Ciudad Neuva, 2012, 560p., ISBN 978-84-9715-272-3.

FERREIRO, A. (Org.). Los Doce Profetas. La Biblia Comentada por Los Padres de la Iglesia. Antigo Testamento 16. Madrid, Bogotá, Buenos Aires, México, Montevideo e Santiago: Ciudad Neuva, 2007, 432p., ISBN 97884-9715-111-5.

HEEN, E. M.; KREY, D. W. (Org.). Hebreos. La Biblia Comentada por Los Padres de la Iglesia. Novo Testamento 10. Madrid, Bogotá, Buenos Aires, México, Montevideo e Santiago: Ciudad Neuva, 2009, 368p., ISBN 978-84-9715-152-8.

LIENHARD, J. T. (Org.). Éxodo, Levítico, Número, Deuteronomio. La Biblia Comentada por Los Padres de la Iglesia. Antigo Testamento 3. Madrid, Bogotá, Buenos Aires, México, Montevideo e Santiago: Ciudad Neuva, 2003, 480p., ISBN 978-84-9715-046-5.

LOUTH, A. (Org.). Génesis 1-11. La Biblia Comentada por Los Padres de la Iglesia. Antigo Testamento 1. Madrid, Bogotá, Buenos Aires, México, Montevideo e Santiago: Ciudad Neuva, 2003, 256p., ISBN 978-849715-033-0.

MARTIN, F. (Org.). Hechos de los Apóstoles. La Biblia Comentada por Los Padres de la Iglesia. Nuevo Testamento 5. Madrid, Bogotá, Buenos Aires, México, Montevideo e Santiago: Ciudad Neuva, 2011, 448p., ISBN 978-84-9715-233-4.

MCKINION, S. A. (Org.). Isaías 1-39. La Biblia Comentada por Los Padres de la Iglesia. Antigo Testamento 12. Madrid, Bogotá, Buenos Aires, México, Montevideo e Santiago: Ciudad Neuva, 2007, 368p., ISBN 978-849715-123-8.

SHERIDAN, M. (Org.). Génesis 12-50. La Biblia Comentada por Los Padres de la Iglesia. Antigo Testamento 2. Madrid, Bogotá, Buenos Aires, Mé- 
xico, Montevideo e Santiago: Ciudad Neuva, 2005, 512p., ISBN 978-849715-072-9.

SIMONETTI, M. (Org.). Evangelio según San Mateo (14-28). La Biblia Comentada por Los Padres de la Iglesia. Novo Testamento 1b. Madrid, Bogotá, Buenos Aires, México, Montevideo e Santiago: Ciudad Neuva, 2016, 416p., ISBN 978-84-9715-078-1.

SIMONETTI, M.; CONTI, M. (Orgs.). Job. La Biblia Comentada por Los Padres de la Iglesia. Antigo Testamento 7. Madrid, Bogotá, Buenos Aires, México, Montevideo e Santiago: Ciudad Neuva, 2010, 320p., ISBN 978-84-9715-215-0.

STEVENSON, K.; GLERUP, M. (Orgs.). Ezequiel, Daniel. La Biblia Comentada por Los Padres de la Iglesia. Antigo Testamento 15. Madrid, Bogotá, Buenos Aires, México, Montevideo e Santiago: Ciudad Neuva, 2015, 496p., ISBN 978-84-9715-325-6.

VOICU, S. J. (Org.). Sabiduría, Eclesiástico. La Biblia Comentada por Los Padres de la Iglesia. Antigo Testamento 11. Madrid, Bogotá, Buenos Aires, México, Montevideo e Santiago: Ciudad Neuva, 2015, 512p., ISBN 978-84-9715-334-8.

WEINRICH, W. C. (Org.). Apocalipsis. La Biblia Comentada por Los Padres de la Iglesia. Novo Testamento 12. Madrid, Bogotá, Buenos Aires, México, Montevideo e Santiago: Ciudad Neuva, 2010, 576p., ISBN 978-849715-191-7.

WRIGHT, J. R. (Org.). Provérbios, Eclesiástés, Cantar de los Cantares. La Biblia Comentada por Los Padres de la Iglesia. Antigo Testamento 10. Madrid, Bogotá, Buenos Aires, México, Montevideo e Santiago: Ciudad Neuva, 2007, 544p., ISBN 978-84-9715-135-1.

\section{CLIE}

ALEXANDER, T. Desmond; BAKER, David W. (Eds.). Compêndio de las Ciencias Bíblicas Contemporáneas: Diccionário del Antigo Testamento Pentateuco. Viladecavalls: CLIE, 2012, 944p., ISBN 978-84-8267-699-9. ARNOLD, Bill T.; WILLIAMSON, H.GM. (Eds.). Compêndio de las Ciencias Bíblicas Contemporáneas: Diccionário del Antigo Testamento -Históricos. Viladecavalls: CLIE, 2014, ISBN 978-84-8267-700-2.

MILLOS, Samuel Pérez. Mateo. Comentario Exegético al Texto Griego del Nuevo Testamento. Viladecavalls: CLIE, 2009, 2141p., ISBN 978-848267-555-8. 
MILLOS, Samuel Pérez. Marcos. Comentario Exegético al Texto Griego del Nuevo Testamento. Viladecavalls: CLIE, 2014, ISBN 978-84-8267-8641 .

MILlOS, Samuel Pérez. Hechos. Comentario Exegético al Texto Griego del Nuevo Testamento. Viladecavalls: CLIE, 2013, ISBN 978-84-8267-9242 .

MILlOS, Samuel Pérez. Romanos. Comentario Exegético al Texto Griego del Nuevo Testamento. Viladecavalls: CLIE, 2011, ISBN 978-84-8267553-4.

MILLOS, Samuel Pérez. Gálatas. Comentario Exegético al Texto Griego del Nuevo Testamento. Viladecavalls: CLIE, 2013, ISBN 978-84-8267-8405.

MILlOS, Samuel Pérez. Efésios. Comentario Exegético al Texto Griego del Nuevo Testamento. Viladecavalls: CLIE: 2013, ISBN 978-84-8267-5572 .

MILLOS, Samuel Pérez. Colocenses. Comentario Exegético al Texto Griego del Nuevo Testamento. Viladecavalls: CLIE, 2015, ISBN 978-84-8267902-0.

MILLOS, Samuel Pérez. $1^{a}$ y $2^{a}$ Tesalonicenses. Comentario Exegético al Texto Griego del Nuevo Testamento. Viladecavalls: CLIE, 2014, ISBN 97884-8267-865-8.

MILLOS, Samuel Pérez. Hebreos. Comentario Exegético al Texto Griego del Nuevo Testamento. Viladecavalls: CLIE, 2009, ISBN 978-84-8267-5565 .

MILLOS, Samuel Pérez. Santiago. Comentario Exegético al Texto Griego del Nuevo Testamento. Viladecavalls: CLIE, 2011, ISBN 978-84-8267-5305.

MILLOS, Samuel Pérez. Apocalipsis. Comentario Exegético al Texto Griego del Nuevo Testamento. Viladecavalls: CLIE, 2010, 1382p., ISBN 97884-8267-558-9.

\section{CNBB}

COMISSÃO LUTERANA-CATÓLICO-ROMANA PARA A UNIDADE. Do conflito à comunhão: comemoração conjunta Católico-Luterana da reforma em 2017. Relatório (2015). São Leopoldo, RJ: CNBB, 2015.

CNBB. Comunidade de comunidades: uma nova Paróquia. A conversão pas- 
toral da Paróquia. Documento da CNBB 100. Brasília: CNBB, 2014, $136 \mathrm{p}$.

\section{Ediciones Sígueme}

BOROBIO, Dionísio. Celebrar para vivir: liturgia y sacramentos de la iglesia. Salamanca (España): Ediciones Sígueme, 2003, 640p., ISBN 978-84301-1509-9.

BOROBIO, Dionísio. El sacramento de la reconciliación penitencial. Salamanca (España): Ediciones Sígueme, 2011, 430p., ISBN 978-84-301-1772-7.

BOROBIO, Dionísio. Historia y teología comparada de los sacramentos: el principio de la analogía sacramental. Salamanca (España): Ediciones Sígueme, 2012, ISBN 978-84-301-1798-7.

BOROBIO, Dionísio (Ed.). La celebración en la Iglesia I: liturgia y sacramentología fundamental. Salamanca (España): Ediciones Sígueme, 2006, 792p., ISBN 978-84-301-0956-2.

BOROBIO, Dionísio (Ed.). La celebración en la Iglesia II: sacramentos. Salamanca (España): Ediciones Sígueme, 2008, 792p., ISBN 978-84-3011064-3.

BOROBIO, Dionísio. Misión y ministerios laicales. Salamanca (España): Ediciones Sígueme, 2001, 384p., ISBN 978-84-301-1437-5.

BOROBIO, Dionísio. Sacramentos y sanación: dimensión curative de la liturgia cristiana. Salamanca (España): Ediciones Sígueme, 2008, 144p., ISBN 978-84-301-1680-5.

\section{EDUSP}

BLATYTA, Dora Fraiman. Forma e uso dos verbos em hebraico. São Paulo: EDUSP, 2015, 216p., ISBN 978-85-314-1264-6.

\section{Sal Terrae}

AGUSTIN, George (Ed.). El evangelio de la misericordia. Maliaño (Cantabria) España: Sal Terrae, 2016, 232p., ISBN 978-84-293-2503-4.

KASPER, Walter. El desafio de la misericordia. Maliaño (Cantabria) España:

Sal Terrae, 2015, 120p., ISBN 978-84-293-2552-2. 


\section{Senado Federal}

VIDE, D. Sebastião Monteiro da. Constituições primeiras do Arcebispado da Bahia (1707). Brasília: Senado Federal, 2007, 526p.

\section{Três Estrelas}

FEBVRE, Lucien. Martinho Lutero, um destino. São Paulo: Três Estrelas, 2012, 359p.

Vida Nova

ANDERSEN, F. I. Jó, introdução e comentário. São Paulo: Vida Nova, 1984, 296p., ISBN 978-85-275-0157-6.

\section{Vozes}

SICRE DÍAZ, José Luis. Introdução ao Antigo Testamento. Petrópolis/RJ: Vozes, 2015, 335p., ISBN 978-85-326-1229-8 (5 exemplares).

SICRE DÍAZ, José Luis. Introdução ao profetismo bíblico. Petrópolis/RJ: Vozes, 2016, 535p., ISBN 978-85-326-5241-6 (5 exemplares). 